\title{
Prelúdio à filosofia da diferença: uma leitura do livro La filosofia crítica de Kant
}

Prelude to the philosophy of difference: a reading of the book The critical philosophy of Kant

http://dx.doi.org/10.5007/2178-4582.2014v48n1p176

Edelu Kawahala e Rodrigo Diaz de Vivar y Soler

Universidade Federal de Santa Catarina, Florianópolis/SC, Brasil

\section{Resenha de:}

DELEUZE, Gilles. La filosofia crítica de Kant. Madrid: Cátedra, 2008.

Kant não é, para Deleuze, aparentemente, um filósofo pertencente ao mais alto círculo de pensadores, da envergadura de Spinoza, Nietzsche ou Bergson. Contudo, não devemos enxergar nessa figura o real inimigo conceitual da filosofia da diferença. Esse papel é ocupado pela dialética hegeliana.

Aquilo que eu mais detestava era o hegelianismo e a dialética. Meu livro sobre Kant é muito diferente, gosto dele, eu o fiz como um livro sobre um inimigo procurando mostrar como ele funciona, com que engrenagens, - tribunal da Razão, uso comedido das faculdades, submissão tanto mais hipócrita quanto nos confere o título de legisladores (DELEUZE, Gilles. 1992, p. 14).

Estes seriam os artefatos que Deleuze mobiliza para empreender uma leitura da filosofia crítica sem colocar-se como mero comentador do filósofo alemão. Para além de qualquer hermenêutica, Deleuze exerce, de acordo com Craia (2009), uma apropriação filosófica que toma os conceitos da filosofia kantiana numa perspectiva que atravessa a ontologia e o transcendental, tendo como referência os conceitos de diferença e de repetição.

O modo de operação construído por Deleuze nessa leitura perspectivista é composto pelo agenciamento. Esta ferramenta implica não o elogio, nem o comentário superficial, mas, sobretudo a problematização dos conceitos. Neste sentido, a problematização de um pensamento como o de Kant equivale à construção de uma argumentação que permite, posteriormente, a apropriação e a transposição, de modo que passa-se a percorrer cada campo aberto pelo kantismo, sem necessariamente ser sujeitado pelos dispositivos presentes no método transcendental, pois o pensamento deve ser visto como uma atividade 
que percorre esses campos inferindo os agenciamentos e decompondo suas articulações. Desta maneira, o que interessa para Deleuze (2008) é potencializar, nessa decomposição, a emergência de novos conceitos e apropriações.

Uma vez que a filosofia é a arte de criar conceitos, e talvez mais do que isso, a potência criativa de personagens conceituais, uma apropriação pelo critério do agenciamento só pode ser obtida por meio da experiência. Mas, poderíamos nos perguntar: como é possível experienciarmos o pensamento kantiano sem sermos acossados pelos seus encantamentos presentes tanto no domínio da lógica formal, quanto os de uma moral universal? Circula, em torno desse questionamento, a intencionalidade de Deleuze (2008), em verificar se o que Kant chama de faculdade comporta uma forma superior, ou seja, se determinada faculdade pode elevar-se até sua última potência.

Eis então a primeira constatação: a filosofia, para Kant, é um saber responsável por analisar as condições de possibilidade do conhecimento, e o filósofo é aquele que explora os domínios da razão a partir das suas faculdades. Se, para o empirismo, a razão estava atrelada à concepção de natureza humana, agora ela deve ser entendida como algo subordinado a determinados fins. É justamente contra essa concepção ontológica que Kant tece seus três argumentos.

O primeiro é o de valor. Se os fins da razão levassem apenas ao encontro da essência humana, não haveria finalidade do sujeito ultrapassar sua condição de animalidade. O segundo argumento é o absurdo. Se o fim último da razão fosse à natureza humana, não seria preferível adotarmos o instinto como meta? O terceiro argumento é o conflito. Para Kant, a razão não é uma faculdade dos meios. Existe um conflito que liga os problemas das necessidades naturais com os problemas de cultura. Conforme aponta Deleuze:

\footnotetext{
Não há dúvida que o racionalismo, por sua vez, reconhecia que o ser racional perseguia fins cabalmente racionais. Mas o que apreende a Razão como fim é, todavia algo exterior e superior: um Ser, um Bem, um Valor, considerados como regras da vontade. Portanto, a diferença entre racionalismo e empirismo não é tão grande como se pressupunha. Um fim é uma representação que determina a vontade (DELEUZE, 2008, p. 13).
}

Esse exterior responsável por sujeitar a razão só pode ser fielmente analisado por meio do método transcendental. De certa forma, um dos grandes desafios explorados por Deleuze em A Filosofia Crítica de Kant é investigar as características desse método. Para alcançar tal objetivo, Deleuze parte do princípio de que o transcendental possui como finalidade instituir uma crítica da razão a partir de dois desdobramentos. Em primeiro lugar, pelo estabelecimento da verdadeira natureza dos interesses e fins da razão. Em segundo lugar, pela elaboração dos meios para realizar esses interesses. Para Deleuze, são esses desdobramentos que estão diretamente ligados ao que Kant chama de faculdade. 
O sentido da palavra faculdade está associado ao papel da representação na construção do conhecimento. Neste sentido, a representação pode aparecer como faculdade de conhecer relativa às idéias de concordância e de conformidade. Da mesma maneira, a representação pode ser vista como faculdade do desejar, isto é, como causa real dos objetos representados. Por fim, pode se fazer presente como faculdade de prazer e de dor relativa aos modos pelos quais o sujeito intensifica sua força vital por meio de juízos e valores. Cumpre ressaltar que o grande problema formulado por Deleuze não consiste em tipologizar essas faculdades, mas justamente abordar o que permite a Kant afirmar a existência, a partir desses modelos, do transcendental. A pergunta a ser realizada é, antes de tudo, metodológica. Como transpor os limites destas faculdades para chegar-se aos fins últimos?

É justamente este questionamento que, aos olhos de Deleuze, não é respondido pelo método transcendental. Na realidade, Kant não está interessado em jogar com essas faculdades explorando ao máximo os seus recursos, mas apenas se preocupa em creditar a elas um bom uso, nos contextos da filosofia do conhecimento, da ontologia e da ética. A constatação de Deleuze é que não existe em Kant uma exploração extrema dessas faculdades, mas apenas operação comedida e organizada. Retornando sempre à fórmula da identidade, a preocupação do filósofo alemão não é inovadora, mas conservadora. Vejamos um exemplo: em relação à faculdade superior de conhecer, a filosofia crítica entende o conhecimento como uma síntese de representações. Neste sentido, para se conhecer algo é preciso, antes de tudo, reconhecer a existência de encadeamentos que estão presentes no apertado espaço de relação entre o a priori e o a posteriori. Na Crítica da Razão Pura Kant (2005), afirma que, embora a síntese a priori ocorra independentemente da experiência, ela aplica-se aos objetos da experiência e não sobre as coisas em si.

A finitude do transcendental é apontada por Deleuze por conta de interesses nos quais está em jogo única e exclusivamente um sistema finito atravessado pelas condições de possibilidade. Nunca é demais lembrar que o estudo que abre A Filosofia Crítica de Kant é dedicado à categorização do que Deleuze chama de jogo entre faculdades receptivas e faculdades ativas. Segundo este autor, existe, num primeiro momento, a sensibilidade intuitiva na qual a faculdade receptiva é debitaria direta e, num segundo momento, a faculdade ativa que acaba por operar como fonte da verdadeira representação. Sendo assim, enquanto a sensibilidade está presente nas faculdades receptivas, a representação está atrelada às faculdades ativas. Essa distinção é importante para demarcar o método transcendental como ferramenta possível para a estruturação de uma ontologia que se efetiva tanto pelo princípio da qualificação, quanto pela submissão necessária da experiência às representações $a$ priori correlativamente às aplicações necessárias ao conhecimento. Sendo assim, pode-se afirmar segundo Deleuze que: 
Transcendental designa o princípio em virtude do qual a experiência remete-se necessariamente a nossa representação $a$ priori. Por esta razão, atrás da exposição metafísica do espaço e do tempo vem uma exposição transcendental. Transcendental qualifica o princípio de uma submissão necessária dos dados da experiência às nossas representações $a$ priori e correlativamente, de uma aplicação necessária das representações a priori à experiência (DELEUZE, 2008, p. 30).

A revolução copernicana em Kant significou um corte epistemológico em relação ao dogmatismo racionalista, substituindo a ideia de uma harmonia entre sujeito e objeto, pelo princípio de uma sujeição necessária do objeto em relação ao sujeito mediada pelo transcendental. A nosso ver, o que Deleuze questiona neste processo é a (im)possibilidade da experiência representativa tornar-se necessariamente uma potência. Fato este que, para Deleuze, implica numa ruptura quase que direta, por parte de Kant, em estabelecer um imperativo do pensamento como uma experiência direta. Ora, se a grande sustentação do transcendental acontece por meio da razão legisladora das próprias formas de conhecer - moralizar e julgar - é porque esse método afasta de si toda e qualquer possibilidade de experienciação. Experienciação esta que, em Nietzsche e Spinoza, foram levadas ao extremo, não só como estilo filosófico, mas como atitude provocativa de vida. A questão, portanto, é deter-se sobre a experiência, vislumbrando desta maneira as finitudes de uma filosofia delimitar um método que pressupõe a razão como a grande legisladora. Afinal, como lembra Deleuze:

A genialidade de Kant, na Crítica da Razão Pura, foi a de conceber uma crítica imanente. A crítica não deveria ser uma crítica da razão pelo sentimento, pela experiência, por qualquer instância exterior. E muito menos o criticado era exterior à razão; não se deveria procurar na razão erros vindos de fora, corpo, sentidos, paixões, e sim ilusões provenientes da razão como tal. Ora, limitado por essas duas existências, Kant concluiu que a crítica deveria ser uma crítica da razão pela própria razão. Não é essa a contradição kantiana? Fazer da razão ao mesmo tempo o tribunal e o acusado, constituí-la como juiz e parte, julgadora e julgada. Faltava a Kant um método que permitisse julgar a razão de dentro, sem lhe confiar, entretanto o cuidado de ser juiz de si mesma. E, de fato, Kant não realiza seu projeto de crítica imanente. A filosofia transcendental descobre condições que permanecem ainda exteriores ao condicionado. Os princípios transcendentais são princípios de condicionamento e não de gênese interna. (DELEUZE, 1975, p. 30):

O desafio empreendido por Deleuze é justamente compreender a filosofia crítica de Kant não somente no âmbito das condições de possibilidade do conhecimento. Neste sentido, não se trata de prescrever uma ontologia, ou 
uma epistemologia, mas sim de percorrer toda essa amplitude de conceitos a partir da exterioridade da experiência. Em outras palavras, Deleuze valese de conceitos kantianos aplicando-os contra Kant, tendo como finalidade provocar uma desestabilização em torno de problemas fundamentais como o papel da razão legisladora e da representação das faculdades, por meio de um procedimento radical, qual seja, o de conceber o método transcendental como um dispositivo.

Até que ponto o transcendental pode chegar? Essa é uma das muitas perguntas formuladas por Deleuze. Uma resposta plausível seria a de que o limite do transcendental encontra-se na afirmação kantiana de que tal método é a condição de qualquer fenômeno possível, pois, para Deleuze, o problema consiste em situar o transcendental como fenômeno do real. Essa perspectiva situaria a filosofia kantiana sob o viés da materialidade da experiência, e não mais sob o critério da experiência possível. Neste sentido, pode-se afirmar que de forma alguma Deleuze rejeita o transcendental, mas procura, a partir da visualização de suas finitudes, intensificar uma nova proposta referendada pela multiplicidade da diferença. Essa releitura implica uma superação da representação, do mesmo, dos jogos de identidade em nome da afirmação de uma filosofia da diferença.

Sendo assim, podemos afirmar que a filosofia da diferença opera uma problematização singular do transcendental em Kant e, ao realizar esta tarefa, potencializa uma nova condição que se move pela experiência e não mais pelos critérios de uma razão legisladora. Uma vez que a tarefa de Deleuze consiste em radicalizar a função da condição de possibilidade, emerge nesse contexto, uma ruptura, um abalo provocado pelo filósofo francês, cuja inscrição encontra-se referendada pelo martelo nietzschiano.

\section{Referências Bibliográficas}

CRAIA, Eladio. C. P. Entre a ontologia e o transcendental: Deleuze, uma apropriação de Kant. Kant e-Prints. Campinas, Série 2, v.4, n.2, p. 307 - 321, jul./dez. 2009. Disponível em: ftp://ftp. cle.unicamp.br/pub/kant-e-prints/Vol-4-2-2009/6-eladio-4-2-2009.pdf. Acesso em: 15/08/2010.

DELEUZE, Gilles. Nietzsche e a Filosofia. Rio de Janeiro: Semeion, 1975.

DELEUZE, Gilles. Carta a um crítico severo. In: DELEUZE, Gilles. Conversações. Rio de Janeiro: Ed. 34, 1992.

DELEUZE, Gilles. La filosofía crítica de Kant. Madrid: Cátedra, 2008.

KANT, Immanuel. Crítica da Razão Pura. Coleção Os Pensadores. São Paulo: Abril Cultural, 2005. 
Submissão em: 25/12/10

Revisão em: 08/08/2013

Aceite em: 02/11/2013

Edelu Kawahala é Mestre em Psicologia pela UFSC e Doutoranda em Teoria Literária pela UFSC.

E-mail: edeluk@gmail.com

Rodrigo Diaz de Vivar y Soler é Bacharel em Psicologia pela UNESC, Mestre em Psicologia pela UFSC, Doutorando em Psicologia pela UFSC e Professor do Centro Univesitário Catarinense UNIVESC.

E-mail:diazsoler@gmail.com 